UDK $004.91+004.81 / 34.01$

\author{
S.O. Kosenko, \\ post-graduate student The Georgy Pukhov Institute \\ for Energy Modelling of NAS of Ukraine; \\ (Ukraine, 03164, Kyiv, 15, General Naumov Str., \\ e-mail: sergey.a.kosenko@gmail.com)
}

\title{
The Main Statements of Ontology Theory and Its Implementation in the System of Legal Knowledge
}

The paper presents general information about a notion "ontology" historical derivation. Apart from this different ways of ontology term transformation for usage in artificial intelligence systems are analyzed. Ontology is regarded there as a complex of knowledge for clear representation of the data about events, phenomena, general and special notions concerning society, laws and the world. Apart from this, ontology is developed to supply different information about the subject of interest. There are a number of ontologies, namely surface, top, domain ones and so on, which form a base for further development of knowledge based systems and their application in combination with artificial intelligence and a set of databases for improving the process of logical thinking and making relevant decisions. Ontologies are of particular importance for law and legal theory for rule formalization, accepting court resolutions and providing information about precedents and untypical cases. The ontology design criteria are also given along with the peculiarities of their application in legal domain. Ontologies are formed with specific goals, but there are no ways of forming their contents and design. The main task to be followed in ontology creation deals with the strict and clear formulation of the idea of ontology with allowance for the link between different ontologies.

Ke yw ords: ontology, law, artificial intelligence, conceptualization, domain of law.

Подано загальні відомості про походження поняття «онтологія» та проаналізовано шляхи його подальшої трансформації для використання в системах штучного інтелекту, де онтологія розглядається як комплекс знань, що надають певну інформацію про об'єкт дослідження. На теперішній час розроблено низку різноманітних онтологій, а саме поверхневі, топові, доменні тощо, котрі є основою при розробці системи штучного інтелекту 3 використанням накопичених знань та баз даних для удосконалення процесу логічного мислення і прийняття відповідних рішень. Особливого значення набули онтології в правознавстві для формалізації законів, прийняття судових рішень та надання інформації про певні прецеденти та нетипові випадкі. Наведено критерії дизайну онтологій, а також особливості їх застосування в правовому домені. Формування онтологій має специфічні завдання, однак відсутні які-небудь способи формування їх змісту та дизайну. Головне

(C) S.O. Kosenko, 2018

ISSN 0204-3572. Електрон. моделювання. 2018. Т. 40. № 1 
завдання, якого слід дотримуватися при створенні онтології, полягає у суворому і чіткому формулюванні суті онтології, враховуючи зв'язок між різними онтологіями.

Ключ ов і слов а: онтологія, право, штучний інтелект, концептуалізація, правовий домен.

General information about ontology. Representation of the complex of generally accepted knowledge is based on conceptualization combining objects into the singe unit, concepts and other logical categories that simultaneously form certain concept and thus, related between themselves with respective links and relations [1]. Therewith the conceptualization itself is a speculative and simplified view on the real world, which we would like to image in one way or another. Any knowledge basis and the system built on the accumulated knowledge as well as the factors created with the help of certain knowledge subject to conceptualization explicitly or implicitly [2].

Ontology is the clear specification of conceptualization. It is known that this word was borrowed from philosophy where ontology is considered as the systematized report of existence. At the same time the systems of artificial intelligence consider existence as the ability to any kind of representation. When information about a specific area of knowledge is represented in a declarative formalism, the number of conceptual objects covered by it is called the totality of discourses. Information about conceptual objects as well as existing interrelations between themselves is located at the respective thesaurus of terms with the help of which specially developed software familiarizes the user with that sphere of knowledge presented in ontology. With this purpose a computer program represents ontology in the form of informative terms, and the definitions unite names of the objects into the totality of discourses that are the classes, relations, functions, etc., accompanied with text from which one can easily understand the meaning of objects' names and the restrictions imposed on the interpretation and usage of terms. It is generally accepted that ontology is the provision of consistent theory. Ontology is very often equated with taxonomic hierarchies of classes, without defining the classes themselves and their relation to the classification; however, ontologies actually represent a much broader category [3]. Besides, ontologies cannot be limited by the conservative definitions only that are such explanations in the sense of traditional logic that only introduce this terminology but do not give any information about the things related to these terms. For specification of conceptualization, firstly, it is needed to formulate axioms that define possible ways of interpretation of the specified terms.

As a rule general ontologies are used to describe the tasks that are envisaged for execution by every factor in such a way that they exchange information about the discourse domain itself, and this might give the possibility to refrain from the simultaneous application of all logic theory. The conclusion is that the factor be- 
longs to ontology under the conditions of its real subordination to the requirements and definitions of ontology. The idea of ontology subordination is built on the knowledge level perspective (KLP) that was formulated by Newell (1982); according to it the factor is endowed with knowledge, in so doing it remains independent of the representative symbols system embedded in it [4]. Knowledge is transferred to the factor with the purpose to follow up its actions. Due to this the factor can «know» something only in case when it acts as if it knows certain information, under these conditions its actions are logic and consistent for reaching the final target. Action of the factors, including computers and servers, can be observed with the help of the functional interface on the dialogue base «assertion-question»; in its frame the user interacts with the factor asserting something and simultaneously asking the question [5].

In practice, the general ontology defines the glossary of concepts and terms with the help of which the exchange of questions and assertions between factors is done. Usage of the glossary is done following ontological responsibilities that by default are the agreements to use the unified glossary in the comprehensive and consistent manner. Each of these factors using the unified glossary should not mandatory have the entire sum of knowledge fixed in ontology. On the contrary, some factors give answers to one part of the questions arising from application of the unified or consolidated glossary and the rest give answers to the other one, so in this way they complement one another.

In other words, responsibilities of general ontology are the guarantee of harmony but in no way of exhausting in provision of information by means of questions and assertions arising from usage of the glossary embedded in ontology.

Engineering criteria of ontologies. Ontologies do not originate by themselves, they are developed. When we put a target to represent something in ontology, we have to find certain design decisions. In order to control and evaluate the design there should be objective criteria that are based on the concept of the final artificial object but not on the priory concepts on naturalness or reliability. In this regard Gruber [6] proposed the set of criteria for creation of ontologies; their task is dissemination of knowledge and development of interaction between the programs based on mutual conceptualization. So, let us proceed to the explanation of every criterion.

Clearness. Ontology must clearly transfer the notions embedded in every term. Definitions should be objective and independent of the social context and their complexity. There is the formalism that is used for this purpose. When the definition can be presented in the form of the logic axioms so it should be done like this. When it is possible the complete definition (assertion that is defined by the necessary and sufficient conditions) prevails over partial definitions (assertion that is defined as either necessary or sufficient conditions). All definitions should be given in common language. 
Coherence. Ontology should be coherent that is it should sanction such conclusions that are in concord with the definitions. At least, the axioms in definitions should be logically consistent. Coherence should also apply to the concepts that are usually presented by the common language in documentation and examples. When the expression derived from the axiom contradicts the definition or example, ontology should be considered incoherent.

Prevalence. Ontology must be developed in such a way that to foresee the usage of the complex glossary. It must create a conceptual basis for the line of expected tasks, in so doing these data presentation should be organized in such a way that to give a possibility to expand deep the foundation ontology. In other words, a user should have a possibility to determine new special purpose terms using already existing complex glossary without revision of already existing interpretations and concepts.

Coding minimum error. Conceptualization specification should be done at the level of knowledge independent of the concept coding with the help of symbols. Deviation from the embedded concept sense occurs when the choice of the representation variants is developed only with the purpose of convenience for indexing and realization. Coding error must be minimized as the same factors of knowledge dissemination could be used in various representation systems and diverse styles of information presentation.

Minimal ontological responsibility. Ontology should require minimum ontological responsibility sufficient for support of the planned activity of knowledge dissemination. Ontology should require minimum responsibility with regard for the artificial intelligence under modelling, giving the possibilities to the parties involved in the ontology to freely specify and illustrate ontology in the way they need it. As the ontological responsibility is based on the consistent application of complex glossary, so it can be minimized by elaboration of the weakest theory (taking into consideration the biggest models) and giving explanation only to the terms that have significant meaning for information transfer related to the theory. Ontology is subjected to some other purpose than the simple data base and thus, its application is related to the attraction of completely different concept of representative sufficiency. General ontology must evaluate the glossary only for presentation of domain information, whereas the data base can comprise information that is necessary for resolution of problems or presentation of responses to any requests with regard for the domain.

Design trade-off decisions. Ontology design along with other problems requires trade-off decisions between criteria. However, criteria, by their nature, mostly do not differ. For example, with the purpose of clarity the definition must restrict the possibility of term interpretation. Minimization of ontological responsibility in its turn means elaboration of the weak theory; under these condi- 
tions the existence of other models is admitted. These two targets do not contradict each other. Clarity criterion analyses the definition of terms while the ontological responsibility is related to information on conceptualization. While taking the decision that there are reasons for distinction, an immediate brief explanation of differences should be done.

Another apparent contradiction exists between the prevalence and ontological responsibility. Ontology that envisages fulfilment of the tasks line does not contain complex glossary that is sufficient for providing of information about all these tasks. Thus, there is the necessity to increase responsibility in compliance with the expansion of complex glossary. Resilient ontology that is the one which can expand and increase can specify very general theory but contain the representative apparatus for determination of needed specializations.

Both the ability to expand as well as the ontological responsibility comprises the concept of sufficiency or adequacy [7].

In traditional data modelling the ontology is usually defined with the help of information messages or data base diagram. As the purpose is the preparation and writing of distinct information that do not depend on specific data or programming language, the KIF (knowledge interchange format) is used [8]. Each ontology defines the complexes of classes, interrelations, functions and sizes of the objects for any discourse domains, it also comprises axiomatising in order to restrict interpretation. The communication language that arises under such conditions is a domain-specific specification of conceptualization.

Peculiarities of ontologies. Trends of ontologies applications are various. This determines the difference of functions that ontologies perform according to each trend. Due to this, while engineering ontology, one should take into consideration the trend where the ontology is planned for application as well as its role in attainment of the ultimate goal. Here, one should analyse the most important ontology functions [9].

Obtaining knowledge is a rather complicated process, although it is critical for engineering knowledge-depended systems. It was considered for a long time that problems precisely arising from knowledge obtaining are the stumbling rock for wide application of the systems built on knowledge. It is clear that the quality of such systems to a large extent is determined by the knowledge that is embedded it them. The task should be executed in a systemic way, in so doing the obtained knowledge is arranged in coherent structure.

Ontology that can be applied for specification of knowledge base creates very convenient basis for realization of knowledge obtaining process.

The structure for knowledge obtaining should have the following features:

It informs us about the thing we need in order to obtain the knowledge about something and also what specific knowledge we need to receive about specific things and what type of information about them we can ignore. 
Ontology structure creates the grounds for data acquisition process.

Ontology determines errors in the obtained knowledge that must be corrected and also incompleteness in knowledge that must be compensated. Under these conditions ontology must clearly identify when the knowledge obtaining process reaches its culmination.

Ontology can be used to search for inconsistencies and uncertainties. It is especially useful when several experts do not have a clear view on future usage of the domain.

Very good example of ontology intended for obtaining knowledge is Protege that is widely used in various software applications [10].

Knowledge dissemination. The second important function of ontologies is the knowledge dissemination between applications. It often happens that several applications impose common requirements upon knowledge. That is why due to complexity of data acquisition the possibility to use knowledge that is already presented in other application seems very perspective. However, there is the difficulty because we do not have any guarantees that the knowledge will be presented in the same way. For example: thus, a knowledge base can have a parent with three family relationships and indicate a father or mother by their place in family relationships. Other knowledge base can have for every person two family relations and distinguish the fathers from the mothers by applying logical conditions to sex determination. To make the knowledge dissemination happen inconsistencies must be settled. This, in its turn, requires availability of glossary description in the applications that are given by ontology. Given this expected ontology will supply presentation harmonization means of different knowledge bases. That is why the role of ontologies is analogue to the integration diagram in the data base. Typical example of the knowledge dissemination is systemic computer web that has concentrated a great deal of contemporary ideas on ontology.

Reusage of knowledge. The problems which are quite similar to those encountered in the dissemination of knowledge also occur in cases when we want to apply a system of knowledge that has been developed for one application to another one. Here the problems can be lesser as we do not try to receive at any cost an access to the knowledge available in other system and vice versa, trying to adapt the existing data base to our requirements. However, we really require that the suppositions used in the design and reduced meanings of the terms will be easily accessed and therewith the needed documentation on this issue must also be present in the ontology [11].

Verification and validation. A lot of systems based on the verification and validation of knowledge are simply built on the verification procedures imposed by the experts or, besides of this, on experts' ideas regarding the perspective of final input data obtaining. Principal verification and validation require availabi- 
lity of several independent specifications; with their regard the system can be verified and accepted. There are adduced arguments, that the use of such function by ontologies can occur through clear delineation of the system objectives and attribution to them an objectivity nature [12].

The systems based on a certain body of knowledge are often built not only with the aim of wide application but with an attempt to understand the processes of artificial logical thinking of a particular domain. At the same time it is often very important to understand the system thoroughly by means of its self-actualization. It is also equally difficult to make an intelligent comparison of two implementations based on different approaches. However, if we have the description of such systems in terms of their ontologies then, the understanding and comparison can be done on the level of conceptualization. This can be possible, since under such conditions discrepancies in the approaches become rather explicit, and this facilitates the explanation of their weak and strong features in case of intellectual analysis of court cases through the prism of current legislation. This level is useful for comparison, for example, of the factors that are used in CATO [13] or sizes with HYPO [14], or comparing CATO with the changes that depend on the usage of certain rules that have been proposed by Prakken and Sartor [15]. Ontology engineering with the purpose of suppositions that are the base of system realization gives the possibility to clarify to some extent the understanding of domain in the limits of which it operates.

Types of ontologies. Within the limits of basic definition of ontologies there are a lot of possibilities for various modifications that is quite natural under the terms of potential variation existence in motivations. It is on this basis that different types of ontologies originate $[16,17]$.

Surface ontologies. The simplest variant out of all when the ontology is built of the line of hierarchy placed terms. Such ontology can resemble the reference book similar to one that is used in the information-and-search system for already long time. The task of such ontology is mainly to assist in information search and therewith augmentation or reduction of the data base able to create hierarchy structure depending on the bigger or lesser quantity of the answers that can be obtained for the initial request. The Word net [18] is the most famous and wide spread ontology of this type.

Higher or upper ontologies. Higher or upper ontology tries to describe fundamental categories that can be applicable to all domains. In this sense it becomes a hierarchical peak and being engineered has the purpose to make evident and comprehensive certain domain conceptions that belong to the set of fundamental categories. Usually, upper ontology begins from such a category as, for example, the "thing" and then gradually goes down through such categories, namely, tangible or intangible things but stops not far from the special things, in- 
cluding machines. Events, persons and relations as well as, perhaps, concepts that have relation to the time and action may likely be found in such ontology. CYC is the most famous ontology of such type [19].

Domain ontology. Domain ontology is directed at creation of concepts that are fundamental for a certain domain. Thus, in the sphere of law we usually expect the ontology to contain such concepts as the law, legal entity and rule.

Several such ontologies are known that have been specially designed for application in the sphere of law. Here, first of all, it is worth mentioning the Valente's functional ontology [20] and frame-based ontology of Van Kralingen and Visser [11,21].

Attachment ontologies. Attachment ontology contains very detailed and specific concepts that give the possibility to perform a separate task within the limits of defined fragment in the sphere of law. Such ontology will contain such motions as, for example, "break in the employment", "employer", "employee", etc. In legal domain such ontologies are usually called law-specified ontologies because they provide information about concepts and notions that are used in the specific law. Visser (1995) gives the example of such ontology for the domain related to the benefits of unemployed in Holland [11].

Attachment ontology can be considered as the foundation for creation of hierarchy, which then must serve for evolution of upper ontology into the domain one. The latter can be used for transformation into the attachment ontology.

Usually attachment ontologies contain details of features, values and axioms that are absent in the surface ontologies although they, as a rule, contain information about all these three information levels [9].

Ontologies of the artificial intelligence for the law. McCarty developed the Language of Legal Discourse (LLD) that can be considered the first try to offer ontology of the artificial intelligence in the law [22]. The purpose of the development was a creation of the language that can mirror the structure of the legal language and thus was suitable for representation of legal knowledge. The language comprised together with the atomic formula a lot of types of horn type law acts, inserts of ancillary claims that comprise conclusions, objections, and rules of silent consent (tacito consensu), prototypes and inconsistencies. In addition the proposed program had a radical feature allowing consideration of the representative features problem, including those having certain relation to time, actions or deontic concepts with regard for permission and obligation.

Thus, this language had a lot in common with the upper ontology. Analysing law concepts McCarty stressed that their definitions were not sufficiently profound because the law concepts were not completely formed, were changing with time and were improved during the theory development. In this respect, he conceptualized law concepts, using therewith a set of mandatory invariant con- 
ditions, set of concept types, and set of methods in order to transit from one type of concept to another. In order to understand how the LLD can be changed into the domain ontology one should pay attention to the variant of using LLD for representation of the concept for the property right [23].

The "Norm" developed by Ronald Stamper was the other early try to use formalism for creating the ontological basis for the law [24]. The author hoped that the offered formalism could be applied in the social system models for which he saw only one law. The Norm has three important ontological concepts:

factors modify and regulate real world by means of actions for which they are responsible;

behavioural variants are associated with the factors and characterise them;

realizations are certain conditions that are created by execution of certain actions.

Despite the greater perfection of the mentioned approach its application in the artificial intelligence systems in the law was limited.

Legal ontology domains filled with concrete content started to be created in the mid-nineties of the twentieth century. Among them certain place was occupied by the mentioned above functional [20] and frame-based ontology [21]. Both are presented in the moderate quantity of details and formalized with the help of the same language for description of ontologies called "ONTOLINGMA" [25].

In Valente's functional ontology the law is understood as a tool for a change or behaviour modification with the purpose of social demands implementation. He differentiated six categories of the law knowledge:

1) Informative knowledge that ascribes an informational status to the situations by the binary principle: prohibited or mandatory. It should be mentioned that just these two conditions of the cases are considered here the objects of deontic functions, and the actions that realize them, originate from them by their normative status.

2) Knowledge of the real world describes the real world that is controlled with the help of the terms and normative knowledge and in this way can be considered as the interface between (not legal) general knowledge content and normative knowledge.

3) Obligatory knowledge: this is such knowledge that gives the possibility to violate the norms that are defined for certain factors.

4) Reaction knowledge is the knowledge that describes the sanctions that can be applied to those responsible for the norm violation.

5) Meta-legal knowledge describes the way how the legal knowledge should be justified. For example, this knowledge usually comprises the principles of the special law to help in the contradiction resolving in the legal knowledge.

6) Creative knowledge is envisaged for explanation of how the concept of legal knowledge occurs and disappears. 
This ontology creates the basis of "on-line" or "active mode" systems, which Valente describes as the "Legal information server" [26]. The main feature of the system is the storage of information in the form of the tests and with the help of analysis fulfilment system that are interrelated between themselves by general expressions in terms of functional ontology. Key direction of this conceptualisation is to create organizational and concordance principles of legal knowledge especially from the position of the conceptual search. Valente mentions two restrictions for ontology realization. The first is purely practical and related to the fact that modelling with the purpose of this concept promotion is resource consuming, namely requires simultaneous attraction of huge amount of auxiliary means. At the same time it should be recognized that the description of various types of the legal knowledge is presented rather comprehensively, however, the domain model in the system of the active mode "on-line" is rather limited. The second ontology limitation is related to the theoretic aspect namely its ability to specify properly various changes in the legislation and thus adapt to them in a certain sense.

In this connection Valente expressed the following idea: "While all expect that ontology can adequately represent legal knowledge in several spheres of legislation and legal systems, this issue has not yet been tested in practice". Besides, it is not clarified how the functional ontology is consistent with all types of questions that are covered in the legislation. At the same time Valente persuades himself that the ontology can and must serve as the connective line between the theory of the law and the legislation built on the artificial intelligence creating a neutral and independent of any problems medium with the help of which the law theory ideas can be formulated. Due to this, Valente evaluates the strength of the functional ontology as: "Legal argumentation model put into this ontology only with the little likelihood can become a cognitive factor but seems to be illogical and complicated for understanding for an ordinary reader as well as for theoretician of the legal knowledge. Instead, the tasks of ontology are not the visibility improvement, facilitation of perception and explanation of empirical facts of judicial decisions, but on the contrary, search for the most economical way to represent legal knowledge and its use for proper argumentation" [27, 28].

From the last citation it is clear that the task of ontology is, first of all, related with the computerization and creation of the theoretical ground for implementation of computer technologies but not the concordance with the theory of legal knowledge. It is exactly from this perception the functional ontology should be evaluated.

Frame-based ontology of van Kralingen and Visser was created with the purpose of approach improvement to the development of computer information systems in legislation and, in particular, for improvement of effectiveness in 
multiple application of knowledge specifications by reducing their subordination to the specific task. This ontology differs from the ontology designed to be a universal one for the whole legislation as well as law-specific ontology containing concepts with regard to the separate law domain, although, of course, these two ontologies are related between themselves whereas the law-specific ontology can be considered as the detailed general ontology that adapts it to the specific domain [21].

The general ontology divides the legal knowledge into three logic categories: norms, acts and concepts description. For each category the ontology determines the frame structure where all specific attributes of a certain category are listed. Three types of categories together with the specific attributes of some categories in general comprise a unified whole that retains its value and validity for each part of legislation. However, the modelling of legal sub-domain also requires solution of many ontological issues related to the peculiarities of legal problems content of this specific domain. In this regard it is important to note that the law-specific ontology consists of information messages of specific content that have direct relation to the specific law domain and which are used to illustrate the way how the norms, acts and concepts are formed in this law domain. Given all the above, it comes out that the general component can be reused in any of the legal domains, whereas the components of the law-specific ontology can be reused only for execution of various tasks in the limits of this specific domain.

This ontology was used as the basis of FRAMER system for consistent application of the Dutch law of unemployment benefits by means of two operations. During the first stage there is the determination of possibility to render benefits for unemployed with the help of specific classification test, at the second stage there is the planning of the line of actions needed to be implemented in order to reach specific legal decisions [11,29].

The considered second legal ontology also has its drawbacks. Firstly, it is a resource intensive one because it requires simultaneous usage of many auxiliary means, although it is justified by its genericity. Secondly, genericity with regard to the legislation does not make this ontology an obligatory general for other domains. Thirdly, there is the logic question how firm is this ontology linked to the theory of law. Exactly the fact that it is based on the analysis of the theory of law and examines some parts of the legislation imposes a demand to be at least partially agreed with the theory of law.

Thus, two considered ontologies are very different, and at the highest level this divergence has a specific feature. This happens because the ontologies have different final targets in which they start their conceptualization. Thus, in his functional ontology Valente looks for the ways to put into parts the whole legal system, while in the frame-based ontology van Kralingen and Visser seek for 
special building blocks out of which it is proposed to build the law as an object of knowledge. Having such a diversion it is quite natural to know whether any further comparison of these ontologies is appropriate. If, however, delve a little bit further, there is the existence of something in common. Thus, in the frame-based ontology we can find «event classification» and «process classification» as the defined relations. The task of these relations is the concordance of the real event with its presentation in legal documents.

For example, if A physically kills B, so these events are highlighted in the normative description as A performs the murder of B. Exactly this relation between the physical act and departmental description is the object of such category of functional ontology as the "world knowledge". With this in mind, we can see that in two conceptualizations the transition from the ordinary description of the physical act to its description in the language of legal departmental documents is of great importance. So the normative status by two ontologies is defined as a function although in the functional ontology it starts from the situation and is finished by the normative status, and in the frame-based ontology it originates from the approved nor.s. and later transfers into the normative status. Beside, for the former ontology the availability of three peculiarities of normative status is a peculiar feature, whereas in the latter ontology two such concepts as "permitted» and "not declared" are referred to the concept "not violated". Nevertheless, there is the possibility of transition to "situation" of the former ontology from the "act" of the latter ontology built on the basis of the imperfectly developed normative documents where the crack for further act improvement is left [29].

The described two ontologies have become the predecessors of modern ontologies of the artificial intelligence in the law. Among them one should note the Norm that had been developed thanks to the project "Network" that was fulfilled for Italian Investigation Council and the Ministry of Justice [30]. This is the example of the surface ontology that is designed for support and control of a special legal language since the development of standard terminology can contribute more efficient information search of legal knowledge.

"E-Court" ontology [31] was created in the Amsterdam University and is the upper ontology targeted at the Dutch Criminal Code. This detailed ontology is specially designed with the purpose of information provision about the requirements for preparation of legal documents in the courts.

Perhaps, the most perfected ontology, which is the excellent example of ontology application while development of law information systems is the "E-Power" [32] that has been developed within the limits of the project for the Dutch tax organization for incomes". This ontology supports all stages of legal activity starting from the design, which then transit to publication and reaches its culmi- 
nation after application in the penalty system of legislation compliance monitoring. This is done with the help of unified network of ontological models network. Ontology gives opportunities to define the drawbacks and inconsistencies already at the design stage that proves its great potential.

Also, as the example of specific ontology application iPRONTO should be mentioned [33]. This ontology is developed with the purpose of programming factor support regarding to the legal control. iPRONTO is developed on the SUMO that derives from the upper ontology IEEC and acquires its specific features in the frame of the Intellectual property law developed by the World Intellectual Property Organization.

Analysis of existing knowledge through the light of ontological views. Both functional and frame-based ontologies were developed as the predecessors for engineering of knowledge basis with the purpose of its further application based on the usage of certain software and hardware. In order to understand which ontology has certain advantages for support of existing knowledge in the law domain, firstly, one should understand and analyze peculiarities of classic approaches applied in development of artificial intelligence in law. This can be illustrated on the basis of logic programming method consideration that is most clearly represented in the formalization of the British Nationality Law (BNL) [34].

The knowledge base in this case consists of the clearly formulated sentences of the following shape $A \leftarrow B_{1} \ldots$ Bn, which should be interpreted as $A$ is true if all $\mathrm{B}-\mathrm{B}_{1} \ldots \mathrm{Bn}$ are also true. An argument to represent the law in this way is that the majority of legislations are deterministic in their nature, and therefore expanded clear statement can form simple and correct language form, through which it will be possible to characterize accurately the legal definition (Sergot, 1991) [35]. The concept of "expansion" here means that the right parts of sentences may contain literals as "no Bi", and such objections are interpreted as failure. The consequence is that while perception of certain decision involves sufficiency of conditions for its main part the set of all interpretation for this main part is used for provision of necessary condition for the truth of the statement that is embedded into the main part of the sentence. Due to this there were attempts to separate the cases where the instances were either desired or not desired [36]. However, only in the program of BNL the parts of the sentences remained unchanged.

Thus, for the above approach the legal knowledge is represented as a set of definitions, and the definition is implemented as a series of extended clearly defined subordinate clauses designed to provide individually sufficient and collectively necessary conditions for the given concept.

Complete reconstruction of ontology usually requires specification of all possible assertions including also the revision of their interpretations. In their turn, assertions create two natural groups. The first one has definitions in the 
knowledge base and the second one does not have such definitions. The latter can subdivide into the definitions that are provided by the system itself (for example, today's date) and the ones, which are presented by the user as the answer to the question (for example, date and place of birth). Definition availability in informative knowledge base depends on whether the assertion in the law is used for formalization or not.

Such method of conceptualisation envisages several things [9]. Firstly, it stresses that the conceptualisation is not obligatory general but at the same time it is sufficient to be applied for various types of the law. Secondly, it operates on the level of departmental domains. Due to this, at formalization of the law, for example, BNL assertions that are provided to the user are the information about physical actions that are later agreed with the respective program with the departmental decisions. For other types of the law unspecified terms can be referred to the departmental information. All depends on the software abilities to manipulate the definitions. When we attempt to expand formalization adding to it an acquisition of the expert experience in order to facilitate separation and definition of assertions as it has been done in the work [37], so in this case we leave the original conceptualisation and we should admit this. Thirdly, one should emphasize the limited content of the applied assertions. If we accept that this is not always correct (for example, when definitions are presented in the form of assumptions) so we have to perform additional expansions. In this connection, one must remember the criticism expressed by McCarty [38] who wrote:

Legal concepts cannot be adequately represented with the help of assertions. On the contrary, legal concepts are unchanged and openly structured.

Legal laws are not static, but rather dynamic. Due to this, it is not important to apply the theory for the process of legal decision adoption, but it is rather important to build one.

In the process of theory development the correct answers are absent although credible arguments with various powers of conviction for every alternative revision of the law can exist that are used in atypical situations.

We can agree with all thoughts expressed by McCarty. However, since the conceptualization in BNL is intended to be applied only to the terms that were clearly defined in the legislation, it was possible here to compete and adduce a counterargument that the concept proposed by this author was a limitation of approach application and not its denial due to the failure to be applied to the specific law. In his turn, McCarty offered alternative conceptualisation that included three components of the legal concept.

The first one is linked to the set of necessary conditions, set of samples that represent sufficient conditions as well as the set of transformations, which demonstrate relationship between the samples. The first set can be empty, the second 
and the third sets as a rule are open and liable to expansion. As a result, it becomes possible to adapt the structure open to improvement by adding a dynamic aspect, because "application of the concept to a new irregular situation automatically changes the very concept" as the result of expansion of a set of standard samples and/or a set of transformations. Under this interpretation it becomes possible to interpret McCarty's ideas i.e. not such that are an argument for cancelling BNL-type approach, but rather for its improvement, because it provides the first component and the other two keeps in reserve. Any attempt to reconstruct ontologies in this way allows one to better understand the approaches themselves as well as find out differences between the similar approaches like the BNL approach and the approach that permits introducing additional information from the experts' experience and the cases of specific decisions. This also helps to deepen our understanding of relationship between the approaches opposite in their nature.

Conclusions. So, the ontologies are developed with the certain purpose. Assessment of ontology's adequacy or its compliance to certain tasks can be done only in case if the goal is specified. Criteria to which the ontology should comply in order to create the foundation for knowledge representation are much stricter under the terms of completeness and elaboration in comparison to those that are designed to characterise an approach to the legal knowledge system with the purpose of work contextualization.

There are no agreements with regard to what should be specified in the legal ontologies and what specific details should be emphasized. Provided that there are a number of tasks for each subsequent ontology for their further implementation (in terms of actions and sub-domains) we should expect significant differences in what is each ontology. The most important thing in engineering and application of ontology is reliable knowledge on its designation. Besides, one should avoid ontologies with other target that is not embedded into their essence.

The authors submit different conceptualization of the legal domain even when their intentions and ideas are quite similar. In this case there is a quite natural question: "What ontology is true and which one is preferred?" However, this question should be omitted whereas for ontology it's not relevant. The main thing, they must be clearly formulated. Secondly, there must be the possibility to unite them and to define certain relations between them. And thirdly, there are prerequisites for understanding what exactly caused the differences between ontologies. It should be admitted, there is no agreement on basic approaches to creation of legal domain conceptualizing, therefore, it is necessary to seek out and try different alternatives.

Ontologies create useful basis for comparison and analysis of various approaches in the field of artificial intelligence application in legal studies. In this regard, the work [39] indicates that the developers of computer technologies and 
systems must first of all study the theoretical basis of the domain design, under which their developed system is engineered.

There is a certain compromise between the possibilities of the domain multiple usage for fulfilment of various tasks in legislation and epistemological completeness, i.e the ability to cover all terms similar in content. At the lowest level of detailing the ontology must be subordinate to the specific task under fulfilment as well as to the completeness of information provided to the user performing this task.

Differences between the law-specific and universal legal ontology must necessarily exist. In this case the first ontology expresses the basic domain conceptualization and the second one ensures implementation of engineering findings into efficient actualization of computer technologies in legislation.

Studies show that one and the same domain can be conceptualized by various methods. Each method of domain conceptualization causes occurrence of a unique ontology and none of them should have certain advantages over others.

At the present stage the studies focus on a modular approach in the development of legal ontologies, which includes the simultaneous creation of the whole library of ontologies [40-42].

The library of ontologies must contain competing ontologies developed with the only purpose but subject to fulfilment different tasks. Besides, the library must have a place for the so called auxiliary ontologies, which may be united with obtaining a complex ontology. The library must comprise ontologies on various abstraction levels in such a way that elaborated ontologies could be used jointly with more abstract ones. Creation of such a library of ontologies will become a basis for information exchange in legislation between various groups of scientists and for checking of application effectiveness of certain ontologies in the general system of artificial intelligence.

\section{REFERENCES}

1. Genesereth, M.R. and Nilsson, N.J. (1988), Logical foundations of artificial intelligence, Morgan Kaufmann Publishers, California, USA.

2. Fulton, J.A. (1992), Standards working document ISO TC184/SC4/WG3 N103, IGES/PDSES Organization, Dictionary/Methodology Committee, USA, Technical report on the semantic unification meta-model.

3. Enderton, H.B. (1972), A mathematical introduction to logic, Academic Press, San Diego, USA.

4. Newell, R.R. (1982), The knowledge level, Artificial Intelligence, Vol. 18, no. 1, pp. 87127, HYPERLINK «https://doi.org/10.1016/0004-3702\%2882\%2990012-1" \o »Persistent link using digital object identifier" \t «_blank» doi: 10.1016/0004-3702(82)90012-1.

5. Levesque, H.J. (1984), Foundations of a functional approach to knowledge representation, Artificial Intelligence, Vol. 23, no. 1, pp. 155-212, available at: HYPERLINK «https:// doi.org/10.1016/0004-3702\%2884\%2990009-2" \o »Persistent link using digital object identifier" \t «_blank» doi: 10.1016/0004-3702(84)90009-2. 
6. Gruber, T.R. (1995), Toward principles for the design of ontologies used for knowledge sharing, Int. Journal of Human-Computer Studies, Vol. 43, pp. 907-928, available at: HYPERLINK «https://doi.org/10.1006/ijhc.1995.1081" \o »Persistent link using digital object identifier" \t «_blank» doi: 10.1006/ijhc.1995.1081.

7. McCarty, L.T. (2002), Ownership: A case study in representing legal concepts, Artificial Intelligence and Law, Vol. 10, pp. 135-161, doi:10.1023/A:1019584605638.

8. Genesereth, M.R. and Fikes, R.E. (1992), Knowledge interchange format, Version 3.0, Reference Manual, Tech. Rep. Logic-92-1, Computer Science Department, Stanford University, USA, doi: 10.1.1.54.8601.

9. Bench-Capon, T.J.M. and Visser, P.R.S. (1997), Ontologies in legal information systems; the need for explicit specifications of domain conceptualisations, Proceedings of the Sixth International Conference on Artificial Intelligence and Law (ICAIL '97), Melbourne, Australia, 1997, pp.132-141, doi: HYPERLINK «https://doi.org/10.1145/261618.261646" \t» self" 10.1145/261618.261646.

10. Noy, N.F., Fergerson, R.W. and Musen, M.A. (2000), The knowledge model of Protege-2000: Combining interoperability and flexibility, Proceedings of the 12th International Conference on Knowledge Engineering and Knowledge Management (EKAM 2000), Juanles-Pins, France, 2000, pp. 87-98, doi: 10.1007/3-540-39967-4_2.

11. Visser, P.R.S. (1995), Knowledge specification for multiple tasks, Kluwer Law International Hague, Boston, USA.

12. Bench-Capon, T. and Jones, D. (1999), PRONTO: Ontology based evaluation of knowledge based systems, Validation and verification of knowledge based systems, Eds A. Vermesan and F. Coenen, Kluwer Academic Publishers, Dordrecht, Boston, USA, doi: 10.1007/978-14757-6916-6 7.

13. Aleven, V. (1997), Teaching case based argumentation through an example and models, PhD Thesis, The University of Pittsburgh, Pittsburg, USA, doi: 10.1.1.203.1165.

14. Ashley, K.D. (1990), Modeling legal argument, MIT Press, Cambridge, MA, USA.

15. Prakken, H. and Sartor, G. (1998), Modeling reasoning with precedents in a formal dialogue game, Artificial Intelligence and Law, Vol. 6, pp. 231-287, doi: 10.1007/978-94-015-9010-5_5.

16. Ashley, K.D. and Bridewell, W. (2010), Emerging AI and law approaches to automating analysis and retrieval of electronically stored information in discovery proceedings, Artificial Intelligence and Law, Vol. 18, pp. 311-320, doi: 10.1007/s10506-010-9098-4.

17. Bench-Capon, T. and Sartor, G. (2003), A model of legal reasoning with cases incorporating theories and values, Artificial Intelligence, Vol. 150, pp. 97-143, doi: HYPERLINK «https:// doi.org/10.1016/S0004-3702\%2803\%2900108-5" \o »Persistent link using digital object identifier" \t « blank» 10.1016/S0004-3702(03)00108-5.

18. Miller, G.A., Beckwith, R., Fellbaum, Ch., Gross, D. and Miller, K.J. (1990), Introduction to WordNet: an on-line lexical database, International Journal of Lexicography, Vol. 3, no. 4, pp. 361-373, doi: 10.1.1.105.1244.

19. Guha, R.V., Lenat, D.B., Pittman, K., Pratt, D. and Shepherd, M. (1990), CYC: A midterm report, Communications of the ACM, Vol. 33, no. 8, pp. 345-357, doi: 10.1080/08839519108927917.

20. Valente, A. (1995), Legal knowledge engineering: A modelling approach, IOS Press, Amsterdam, Netherlands.

21. van Kralingen, R., Visser, P.R.S., Bench-Capon, T.J.M. and van der Herik, J. (1999), A principled methodology for the development of legal knowledge systems, International Journal of Human Computer Studies, Vol. 51, no. 6, pp. 1127-1154, doi: HYPERLINK «https:// doi.org/10.1006/ijhc.1999.0300" \o »Persistent link using digital object identifier" \t «blank» 10.1006/ijhc. 1999.0300 .

22. McCarty, L.T. (1989), A language for legal discourse I. Basic features, Proceedings of the Second International Conference on Artificial Intelligence and Law, New York, 1989, pp.180-189, doi: HYPERLINK «https://doi.org/10.1145/74014.74037" \t »sself" 10.1145/ 74014.74037. 
23. McCarty, L.T. (2007), Deep semantic interpretations of legal texts, Proceedings of the Eleventh International Conference on Artificial Intelligence and Law, Stanford, CA, 2007, pp. 217-224, doi: HYPERLINK «https://doi.org/10.1145/1276318.1276361" \t "_self" 10.1145/ 1276318. 1276361.

24. Stamper, R.K. (1991), The role of semantics in legal expert systems and legal reasoning, $R a-$ tio Jurist, Vol. 4, no. 2, pp. 219-244, doi: 10.1111/j.1467-9337.1991.tb00094.x

25. Gruber, T.R. (1992), ONTOLINGUA: A mechanism to support portable ontologies, Knowledge systems laboratory, Tech. Rep., Stanford University, California, USA, doi: 10.1.1.34.9819.

26. Valente, A. and Breuker, J. (1999), Legal modeling and automated reasoning with ON-LINE, International Journal of Human-Computer Studies, Vol. 51, no. 6, pp. 1079-1125, doi: HYPERLINK «https://doi.org/10.1006/ijhc.1999.0298" \o »Persistent link using digital object identifier" \t «_blank» 10.1006/ijhc.1999.0298.

27. Valente, A. (2006), Types and roles of legal ontologies, Law and Semantic Web. LNAI 3369 , Ed V.R. Benjamins, Springer Verlag, Berlin, Germany, doi: 10.1007/978-3-540-32253-5 5.

28. Valente, A. and Breuker, J. (1994), A functional ontology of law, Towards a global expert system in law, Eds. G. Bargellini and S. Binazzi, CEDAM Publishers, Padua, Italy, doi: 10.1.1.39.8951.

29. Visser, P. and Bench-Capon, T. (1998), A comparison of four ontologies for the design of legal knowledge systems, Artificial Intelligence and Law, Vol. 6, no. 1, pp. 54-68, doi: 10.1023/A:1008251913710

30. Bolioli, A., Dini, L., Mercatali, P. and Romano, F. (2002), For the automated mark-up of Italian legislative texts in XML, Legal Knowledge and Information Systems JURIX 2002: The Fifteenth Annual Conference, Eds. T. Bench-Capon, A. Daskalopulu, and R. Winkels, IOS Press, Amsterdam, Netherlands, pp. 21-30, doi: 10.1.1.106.6559.

31. Breuker, J., Elhag, A., Petkov, E. and Winkels, R. (2002), Ontologies for legal information serving and knowledge management, Legal Knowledge and Information Systems JURIX 2002: The Fifteenth Annual Conference, Eds. T. Bench-Capon, A. Daskalopulu, and R. Winkels, IOS Press, Amsterdam, Netherlands, pp. 73-82, doi: 10.1.1.59.1956.

32. van Engers, T.M., Gerrits, R., Boekenoogen, M., Glassee, E. and Kordelaar, P. (2001), POWER: using UML/OCL for modeling legislation - an application report, Proceedings of the 8th International Conference on Artificial intelligence and Law, ACM Press, New York, USA, pp. 157-167, doi: HYPERLINK «https://doi.org/10.1145/383535.383554" \t » self" $10.1145 / 383535.383554$.

33. Delgado, J., Gallego, I., Lorente, S. and Garcia, R. (2003), iPRONTO: An ontology for digital rights management, Legal Knowledge and Information Systems JURIX 2003: The Sixteenth Annual Conference, Ed. D. Bourcier, IOS Press, Amsterdam, Netherlands, pp. 111121.

34. Sergot, M.J., Sadri, F., Kowalski, R.A., Kriwaczek, F., Hammond, P. and Cory, H.T. (1986), The British nationality act as a logic program, Communications of the ACM, Vo1. 29, no. 5, pp. 370-386, doi: HYPERLINK «https://doi.org/10.1145/5689.5920" \t »_self" 10.1145/5689. 5920.

35. Sergot, M.J. (1991), The representation of law in computer programs, Knowledge Based Systems and Legal Applications, Ed. T.J.M. Bench-Capon, Academic Press, London, UK.

36. Kowalski, R.A. (1989), The treatment of negation in logic programs for representing legislation, Proceedings of the Second International Conference on AI and Law, ACM Press, New York, USA, pp. 48-69, doi: HYPERLINK «https://doi.org/10.1145/74014.74016" \t »self" 10.1145/74014.74016.

37. Bench-Capon, T.J.M. (1991), Practical legal expert systems: the relation between a formalisation of law and expert knowledge, Computers, Law and AZ, Eds. J. Bennun and M. Narayanan, Ablex, New York, USA, pp. 191-201. 
38. McCarty, L.T. (1995), An implementation of Eisner vs Macomber, Proceedings of the Fifth International Conference on AI and Law, ACM Press, New York, USA, pp. 276-286, doi: HYPERLINK «https://doi.org/10.1145/222092.222258" \t 》_self" 10.1145/222092.222258.

39. Moles, R.N. and Dayal, S. (1992), There is more to life than logic, Journal of Information Science, Vol. 3, no. 2, pp.188-218.

40. Wyner, A. (2008), An ontology in OWL for legal case-based reasoning, Artificial Intelligence and Law, Vol. 16, pp. 271-283, doi: 10.1007/s10506-008-9070-8.

41. Prakken, H. (2006), Artificial intelligence and law, logic and argument schemes, Arguing on the Toulmin Model, Eds D. Hitchcock and B. Verheij, Dordrecht Springer, Berlin, Germany, pp. 91-117, doi: 10.1007/978-1-4020-4938-5_15.

42. Ashley, K. and Bruninghaus, S. (2009), Automatically classifying case texts and predicting outcomes, Artificial Intelligence and Law, Vol. 17, no. 2, pp. 125-165, doi: 10.1007/s10506009-9077-9/

Received 27.10.17

\section{С.А. Косенко}

\section{ОСНОВНЫЕ ПОЛОЖЕНИЯ ТЕОРИИ ОНТОЛОГИЙ И ЕЕ ВНЕДРЕНИЕ В СИСТЕМУ ПРАВОВЫХ ЗНАНИЙ}

Представлены обобщенные данные о происхождении понятия «онтология» и проанализированы пути его дальнейшей трансформации для применения в системах искусственного интеллекта, где онтология понимается как комплекс знаний, представляющих определенную информацию об объекте исследования. В настоящее время разработан ряд различных онтологий, в частности поверхностные, топовые, доменные и другие, которые являются основой при разработке системы искусственного интеллекта с использованием накопленных знаний и баз данных для усовершенствования процесса логического мышления и принятия соответствующих решений. Особое значение имеют онтологии в правоведении для формализации законов, принятия судебных решений и подачи информации об определенных прецедентах и нетипичных случаях. Описаны критерии дизайна онтологий, а также особенности их применения в правовом домене. Формирование онтологий имеет специфические задачи, но отсутствуют какие-либо способы формирования их содержания и дизайна. Основная задача, которая должна быть выполнена при создании онтологии, связана со строгим и четким формулированием сути понятия «онтология», учитывая связь между различными онтологиями.

Ключев в е слов в: онтология, право, искусственный интеллект, кониептуализаичи, правовой домен.

KOSENKO Serhii Oleksandrovich, post-graduate student of the Georgy Pukhov Institute for Energy Modelling of NAS of Ukraine; graduated from Yuriy Fedkovych Chernivtsi National University in 1997. The field of research: artificial intelligence. 
